ORIGINAL ARTICLE

\title{
Expression of p-STAT3 in human colorectal adenocarcinoma and adenoma; correlation with clinicopathological factors
}

\author{
T Kusaba, T Nakayama, K Yamazumi, Y Yakata, A Yoshizaki, T Nagayasu, I Sekine
}

J Clin Pathol 2005;58:833-838. doi: 10.1136/icp.2004.023416

See end of article for authors' affiliations

Correspondence to:

Dr T Nakayama,

Department of Molecular

Pathology, Nagasaki

University Graduate

School of Biomedical

Sciences, 1-12-4

Sakamoto, Nagasaki,

852-8523, Japan;

toshi-n@net.nagasaki-u.

ac.jp

Accepted for publication 4 January 2005
Background: The signal transducer and activator of transcription 3 (STAT3) is a key signalling molecule implicated in the regulation of growth and malignant transformation. Constitutive activation of STAT3 is seen in several tumour derived cell lines, and in a wide variety of human malignancies.

Aims: To examine the relation between p-STAT3 (activated form of STAT3) expression and clinicopathological factors in human colorectal adenocarcinoma and adenoma.

Methods: Immunohistochemical analyses were carried out on tissues from 44 colorectal adenomas and 95 colorectal adenocarcinomas, comprising 18 intramucosal carcinomas and 77 invasive carcinomas.

Results: Seventy seven of these 139 samples $(55.4 \%)$ showed immunoreactivity for p-STAT3. Positive staining for p-STAT3 was seen in 69 of the 95 carcinomas. Only eight of the 44 adenomas showed immunopositivity for p-STAT3, resulting in a significant difference between total adenocarcinomas and adenomas $(p<0.001)$. Among the 95 cases of colorectal adenocarcinoma, $p$-STAT3 immunoreactivity was significantly correlated with the depth of tumour invasion $(p<0.05)$, venous invasion $(p<0.05)$, lymph node metastasis ( $p<0.05)$, and increasing stages of the Dukes' classification $(p<0.01)$. Expression of p-STAT3 was detected by Western blot analysis in two different cultured human colorectal carcinoma cell lines and six colon carcinoma tissue samples obtained at surgery.

Conclusion: This is the first study to report a significant correlation of $\mathrm{p}$-STAT3 expression with the depth of tumour invasion. These findings suggest that $\mathrm{p}$-STAT3 expression is an important factor related to carcinogenesis and/or tumour invasion of colorectal adenocarcinoma.
$\mathrm{T}$ he prognosis of patients with colorectal cancer is based on the depth of tumour cell invasion and the presence of lymph node metastasis. ${ }^{1}$ Usually, these parameters can be determined by microscopic examination of tissue sections from the primary tumour and lymph nodes. ${ }^{2}$ However, it is not always possible to establish a prognosis based only on the histopathological examination of primary colorectal carcinoma specimens. ${ }^{2}$ Recently, the suggestion was made that the occurrence and progression of cancer is related to the activation of an intracellular signalling pathway. ${ }^{3}$ However, the mechanism of the invasion of colorectal carcinomas has not been fully determined.

"There have been no studies on the expression of phosphorylated (activated) signal transducer and activator of transcription in gastrointestinal cancer"

Signal transducers and activators of transcription (STATs) are cytoplasmic transcription factors, and STATs are key mediators of cytokine and growth factor signalling pathways. ${ }^{4}$ At present, seven mammalian STAT genes have been identified..$^{5-7}$ The proteins have a conserved structural organisation consisting of 750-850 amino acids. The binding of a cytokine to its cognate receptor rapidly induces the tyrosine phosphorylation of the receptor by JAK kinases. Such phosphorylated tyrosines provide docking sites for STATs. The STATs themselves are then phosphorylated (p-STATs) and released from the receptor. They can then dimerise and translocate to the nucleus, where they modulate the expression of target genes. ${ }^{8}$ A growing number of tumour derived cell lines, and tumour specimens from human cancers, have been reported to express activated STAT proteins (often STAT3) constitutively. ${ }^{9}$ Constitutive activation of STAT3 has been detected in pancreas, prostate, ovary, head and neck, and other cancers. ${ }^{10-13}$ However, there have been no studies on the expression of p-STAT3 in gastrointestinal cancer. Therefore, our study was conducted to explore the relation between p-STAT3 expression and clinicopathological features in human colorectal carcinoma and adenoma.

\section{MATERIALS AND METHODS}

\section{Cases and tissues}

Forty four human colorectal adenomas and 95 primary human colorectal adenocarcinomas were studied by immunohistochemistry. Of the 95 patients with colorectal carcinoma, there were 52 men and 43 women. The median age was 65.6 years (range, 32-87). Twenty four tumours were located in the rectum, 27 in the sigmoid colon, seven in the descending colon, 19 in the transverse colon, 15 in the ascending colon, and three in the caecum. All tumours were obtained from patients who had undergone endoscopic resection or surgery at Nagasaki University Hospital, Japan between 2000 and 2004. Fifteen specimens of normal colon mucosal tissue, taken from patients without colorectal cancer, were evaluated as normal controls.

Each tumour was assigned a histological type according to the World Health Organisation classification as follows: well differentiated adenocarcinoma, moderately differentiated adenocarcinoma, poorly differentiated adenocarcinoma, and mucinous adenocarcinoma. ${ }^{14}$

Abbreviations: IFN $\alpha$, interferon $\alpha$; IL-6, interleukin 6; p-STAT, phosphorylated (activated) signal transducer and activator of transcription; STAT, signal transducer and activator of transcription 

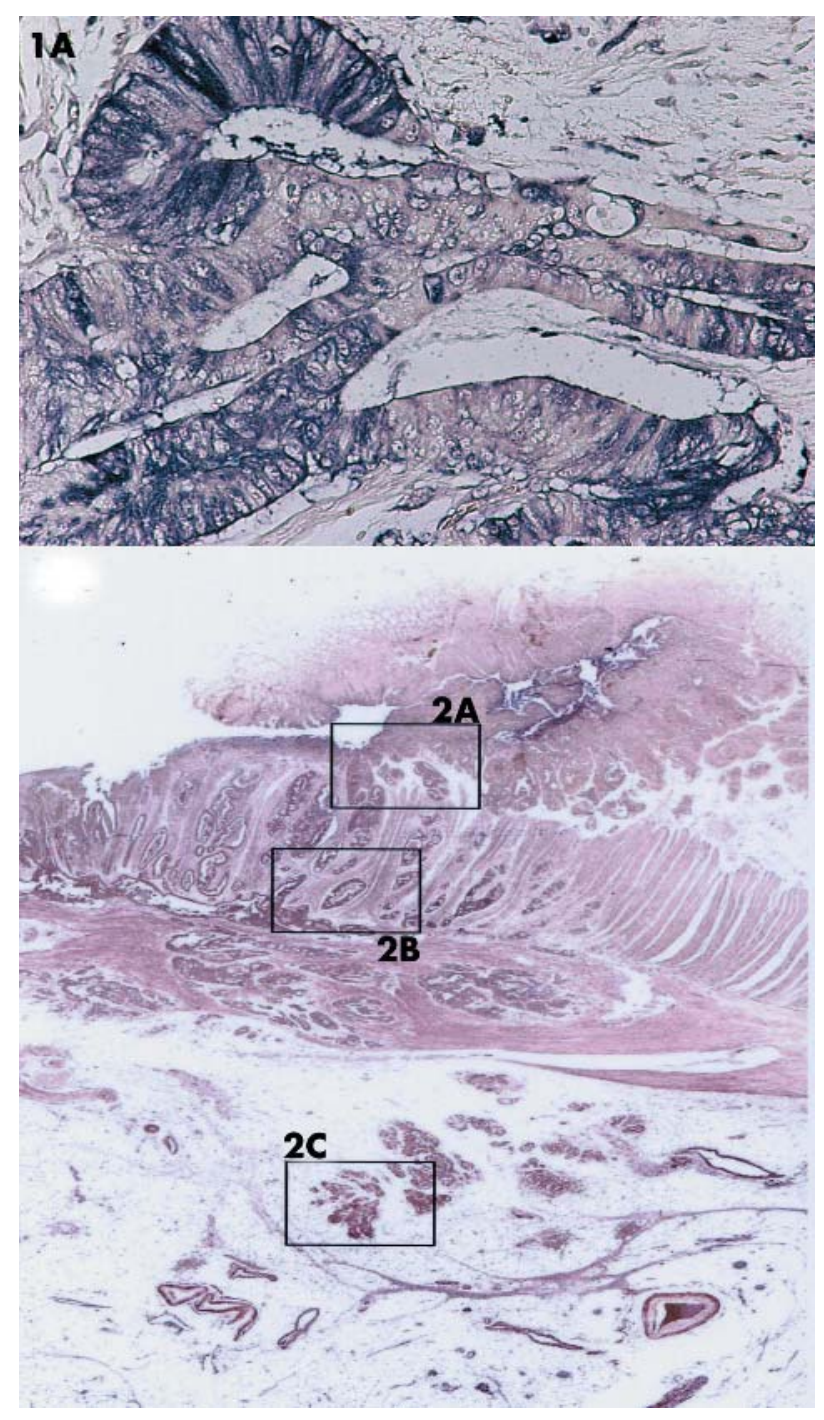

Figure 1 (A) Immunohistochemistry for phosphorylated (activated) signal transducer and activator of transcription (p-STAT3) in colorectal adenocarcinomas. p-STAT3 shows strong nuclear and cytoplasmic expression. (immunoalkaline phosphatase staining; original

magnification, $\times 400)$. (B) Expression of $p$-STAT3 was seen in all layers of this adenocarcinoma (immunoalkaline phosphatase staining; original magnification, $\times 10$ ).

According to the TNM staging system of the American Joint Commission on Cancer, the depth of tumour invasion in each of the carcinomas was classified into five groups, as follows: Tis, carcinoma in situ or limited to mucosa; $\mathrm{Tl}$, invading the submucosa; $\mathrm{T}$, invading the muscularis propria; T3, invading either the subserosa or pericolic tissue; and T4, through the serosa or invading contiguous organs. ${ }^{15}$

Based on the Dukes' classification, the pathological stages of colorectal carcinoma were classified into four groups as follows: A, tumour invading the submucosa or muscularis propria; $\mathrm{B}$, tumour extending beyond the muscularis propria; $\mathrm{C}$, with metastases to regional mesenteric lymph nodes but without evidence of distant spread; and D, with distant metastasis. ${ }^{16-18}$

Lymphatic and venous invasion were studied on routine haematoxylin and eosin stained slides. In addition, the Elastica van Gieson stain was used in all cases. Each parameter was defined as "present" only when invasion was identified with certainty, but defined as "absent" when not seen at all or not seen with certainty. ${ }^{19} 20$
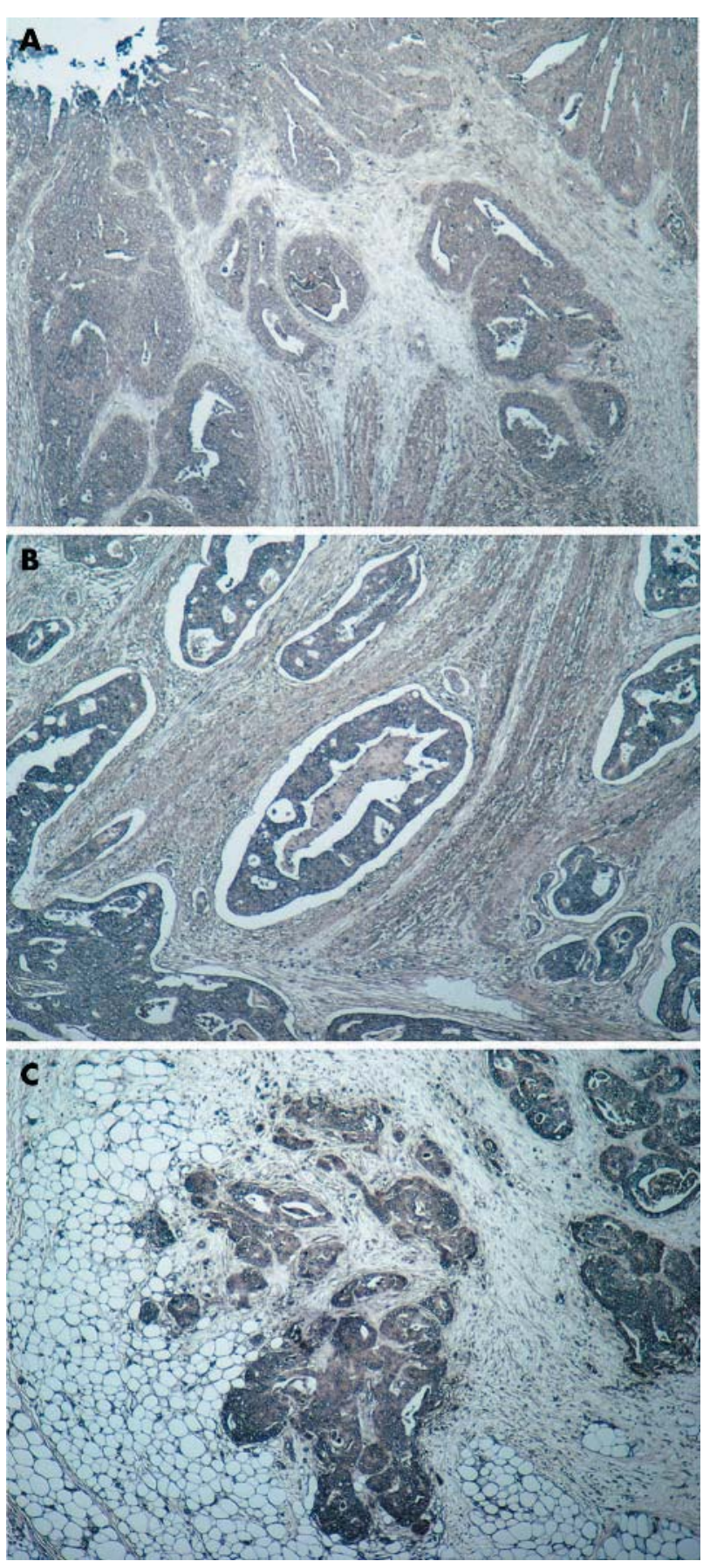

Figure 2 In almost all of the carcinomas studied, the intensity of phosphorylated (activated) signal transducer and activator of transcription (p-STAT3) expression was stronger in the deeper parts of invasion than in the superficial areas. (A) Expression of p-STAT3 in a carcinoma invading the submucosa (original magnification, $\times 60$ ). (B) (original magnification, $60 \times$ ). Expression of p-STAT3 in a carcinoma invading the muscularis propria. (C) Expression of p-STAT3 in a carcinoma invading the subserosa (original magnification, $\times 60$ ).

Lymph node metastasis was defined as "present" only when confirmed histologically.

The diagnosis was established by two independent pathologists ( $\mathrm{T}$ Kusaba and $\mathrm{T}$ Nakayama).

\section{Immunohistochemistry}

Formalin fixed, paraffin wax embedded tissues were cut into $4 \mu \mathrm{m}$ sections, dewaxed in xylene, and rehydrated in 
phosphate buffered saline. Dewaxed sections were preincubated with normal bovine serum to prevent non-specific binding, and then incubated overnight at $4^{\circ} \mathrm{C}$ with an optimal dilution ( $1 \mu \mathrm{g} / \mathrm{mg}$ ) of a primary goat polyclonal IgG against human p-STAT3 (Tyr705; Santa Cruz Biotechnology Inc, Santa Cruz, California, USA). The slides were then incubated with alkaline phosphatase conjugated donkey antigoat immunoglobulin antibody (Santa Cruz Biotechnology Inc). The reaction products were resolved using a mixture of 5-bromo-4-chloro-3-indolyl phosphate and nitroblue tetrazolium chloride (BCIP/NBT; Dako, Carpinteria, California, USA). Primary antibody preabsorbed with excess recombinant p-STAT3 peptide (Santa Cruz Biotechnology Inc) was used for the negative controls. Prostatic tissue served as the internal positive control for p-STAT3 immunostaining. ${ }^{21}$

Analysis of the immunohistochemical staining was performed by two investigators ( $\mathrm{T}$ Kusaba and $\mathrm{T}$ Nakayama). p-STAT3 expression was classified into two categories, depending on the percentage of cells stained: negative, $0-15 \%$ positive cells; positive, $>15 \%$ positive tumour cells.

\section{Cell culture}

Two human colorectal adenocarcinoma cell lines, DLD- 1 and Colo320DM, were cultured at $37^{\circ} \mathrm{C}$ in a humidified atmosphere of $5 \% \mathrm{CO}_{2}$ and $95 \%$ air. DLD-1 was maintained in DMEM/F-12 (Invitrogen Corp, Carlsbad, California, USA) supplemented with $10 \%$ fetal calf serum. ${ }^{22}$ Colo320DM was maintained in RPMI 1640 medium (Invitrogen Corp) supplemented with $10 \%$ fetal calf serum..$^{23}$ Both of these cell lines were provided by the Health Science Research Resources Bank (Osaka, Japan). For the induction of p-STAT3, two human colorectal adenocarcinoma cell lines were stimulated

Table 1 Relations between p-STAT3 immunoreactivity and the pathological features of the tumours

\begin{tabular}{|c|c|c|c|}
\hline & \multirow[b]{2}{*}{$\mathrm{N}$} & \multicolumn{2}{|c|}{ p-STAT3 immunoreactivity* (\%) } \\
\hline & & + & - \\
\hline Normal epithelium & 15 & $0(0.0)$ & $15(100)$ \\
\hline Adenomat & 44 & $8(18.2)$ & $36(81.8)$ \\
\hline Total adenocarcinomas & 95 & $69(72.6)$ & $26(27.4)$ \\
\hline \multicolumn{4}{|l|}{ Differentiation } \\
\hline Well & 45 & $29(64.4)$ & $16(35.6)$ \\
\hline Moderate & 41 & $34(82.9)$ & $7(17.1)$ \\
\hline Poor & 3 & $1(33.3)$ & $2(66.7)$ \\
\hline Mucinous carcinoma & 6 & 5 (83.3) & $1(16.7)$ \\
\hline \multicolumn{4}{|c|}{ Grade of tumour invasion $\ddagger$} \\
\hline Tis & 18 & $9(50.0)$ & $9(50.0)$ \\
\hline T1 & 8 & $4(50.0)$ & $4(50.0)$ \\
\hline $\mathrm{T} 2$ & 5 & $2(40.0)$ & $3(60.0)$ \\
\hline T3 & 61 & $51(83.6)$ & $10(16.4)$ \\
\hline T4 & 3 & $3(100.0)$ & $0(0.0)$ \\
\hline \multicolumn{4}{|l|}{ Lymphatic invasion } \\
\hline Absent & 30 & $18(60.0)$ & $12(40.0)$ \\
\hline Present & 65 & $51(78.5)$ & $14(21.5)$ \\
\hline \multicolumn{4}{|l|}{ Venous invasion§ } \\
\hline Absent & 58 & $37(63.8)$ & $21(36.2)$ \\
\hline Present & 37 & $32(86.5)$ & $5(13.5)$ \\
\hline \multicolumn{4}{|l|}{ Lymph node metastasis§ } \\
\hline Absent & 62 & $40(64.5)$ & $22(35.5)$ \\
\hline Present & 33 & $28(84.4)$ & $5(15.2)$ \\
\hline \multicolumn{4}{|l|}{ Dukes'classification } \\
\hline A & 31 & $15(48.4)$ & $16(51.6)$ \\
\hline B & 30 & 25 (83.3) & $5(16.6)$ \\
\hline C & 31 & $26(83.9)$ & $5(16.1)$ \\
\hline$D$ & 3 & $3(100.0)$ & $0(0.0)$ \\
\hline \multicolumn{4}{|c|}{$\begin{array}{l}\text { *See Materials and Methods for classification of staining intensity; } \\
\text { †Significant difference between total adenocarcinomas and adenomas } \\
(p<0.001), \chi^{2} \text { for independence test; } \neq p<0.01 \text {, Mann-Whitney's } U \text { test; } \\
\S p<0.05, \chi^{2} \text { for independence test; } 9 p<0.001 \text {, Mann-Whitney's } U \text { test. } \\
\text { p-STAT, phosphorylated (activated) signal transducer and activator of } \\
\text { transcription. }\end{array}$} \\
\hline
\end{tabular}

by interferon $\alpha$ (IFN $\alpha$; Cell Signaling Technology, Beverly, Massachusetts, USA). ${ }^{24}$

\section{Immunoblotting}

Specimens and cells were resuspended in ice cold radioimmunoprecipitation buffer $(1 \times$ phosphate buffered saline, $1 \%$ Nonidet P-40, $0.5 \%$ sodium deoxycholate, $0.1 \%$ sodium dodecyl sulfate, ImM phenylmethylsulfonyl fluoride, ImM $\mathrm{Na}_{3} \mathrm{VO}_{4}, 50 \mathrm{mM} \mathrm{NaF}$, and one tablet of complete proteinase inhibitor mixture (Roche Applied Science, Indianapolis, Indiana, USA) $/ 50 \mathrm{ml}$ ) for 10 minutes, sonicated on ice, and centrifuged $\left(12000 \times g\right.$ for 15 minutes at $\left.4^{\circ} \mathrm{C}\right)$. The protein concentration of the supernatant (protein fraction) was determined with the Bradford protein assay (Bio-Rad, Hercules, California, USA). An aliquot of $10 \mu \mathrm{g}$ of protein was mixed with an equivalent volume of $2 \times$ protein loading buffer containing $2 \beta$ mercaptoethanol and boiled for five minutes before loading on to a sodium dodecyl sulfate polyacrylamide gel. After electrophoresis, proteins were transferred on to nitrocellulose membranes using the ECL system (Amersham Biosciences, Piscataway, New Jersey, USA) and blocked in Tris buffered saline with Tween (50mM Tris/HCl, pH 7.5, 150mM NaCl, 0.05\% Tween 20) containing $5 \%$ non-fat dry milk powder. Protein immunoblots were performed using specific antibodies to $\beta$ actin (Santa Cruz Biotechnology Inc), phosphotyrosine (Tyr705) STAT3 (Cell Signaling Technology), and STAT3 (Santa Cruz Biotechnology Inc). The membranes were further incubated with peroxidase conjugated secondary antibodies, and protein bands were visualised using a commercial chemiluminescence detection kit (ECL Plus; Amersham Biosciences), as described by the manufacturer.

\section{Statistical analysis}

The Stat View II program (Abacus Concepts Inc, Berkeley, California, USA) was used for statistical analyses. Analyses comparing the expression of p-STAT3 were performed with the $\chi^{2}$ test for independence and the Mann-Whitney $\mathrm{U}$ test.

\section{RESULTS}

We analysed the correlation between p-STAT3 immunoreactivity and sex, age, and site of the primary tumour, but there were no associations.

Histologically, there were 18 intramucosal carcinomas and 77 invasive carcinomas. All 18 cases of intramucosal carcinoma were well differentiated adenocarcinomas (data not shown). Of the 95 invasive carcinomas, 45 were well differentiated adenocarcinomas, 41 were moderately differentiated adenocarcinomas, three were poorly differentiated adenocarcinomas, and six were mucinous carcinomas. Among the invasive carcinomas, there were eight submucosal infiltrative carcinomas (T1), five carcinomas invading proprial muscle layers (T2), 61 carcinomas reaching the subserosa (T3), and three carcinomas through the serosa or invading contiguous organs (T4). Sixty five patients had lymph node metastasis.

Figure 1A shows a representative example of strong immunohistochemical p-STAT3 staining in an invasive carcinoma, T3 grade. p-STAT3 protein was detected in both the cytoplasm and the nucleus of almost all carcinomas. Figure 1B shows an adenocarcinoma of the invasive type. Expression of p-STAT3 was identified in all cell layers of T3 grade (serosal invasion) invasive carcinomas. Figure $2 \mathrm{~A}-\mathrm{C}$ shows representative examples of immunohistochemical staining for p-STAT3 in each layer. Figure 2C shows more intense staining than fig $2 \mathrm{~A}$ and $\mathrm{B}$. In many cases, the invasive front and peripheral parts of the carcinoma were more intensely stained than the superficial and central parts (fig 2C). 


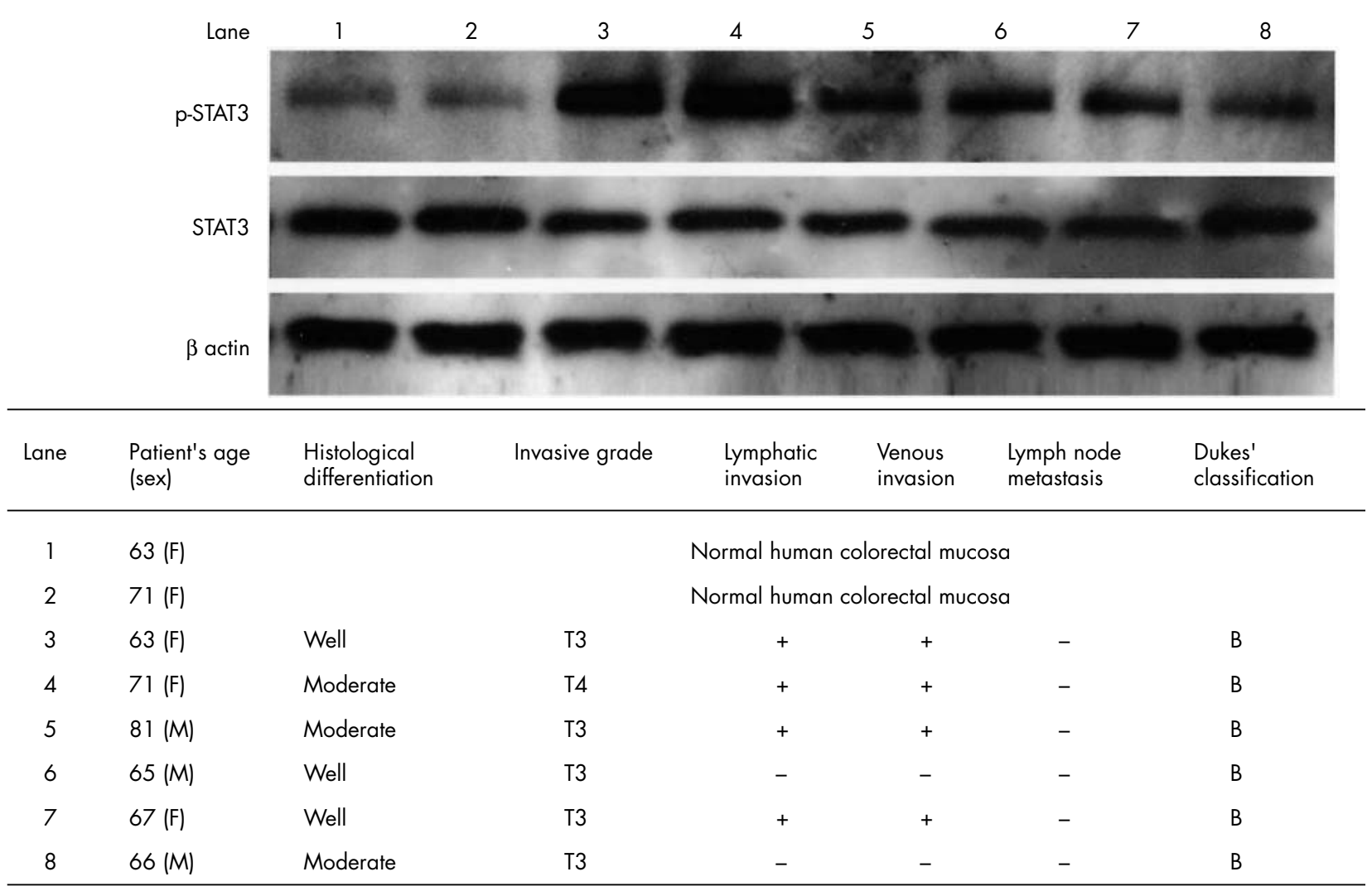

Figure 3 The expression of phosphorylated (activated) signal transducer and activator of transcription (p-STAT3) is lower in normal mucosa (lanes 1 and 2) than in adenocarcinoma (lanes 3-8). There is no difference in the expression of STAT3 between the normal mucosa and carcinoma tissues. $\beta$ Actin was used as an internal protein control.

Table 1 shows p-STAT3 immunoreactivity of human colorectal tumour cells. p-STAT3 was not expressed in the 15 cases of normal colorectal epithelium. In the adenomas, only eight of 44 showed immunoreactivity for p-STAT3. In contrast, 69 of 95 colorectal adenocarcinomas showed immunoreactivity for p-STAT3. Immunoreactivity was noted in nine of the 18 intramucosal carcinomas, whereas strong immunoreactivity was found in 60 of the 77 invasive carcinomas. Statistical analysis showed a significant difference between adenocarcinomas and adenomas $(\mathrm{p}<0.001)$.

Table 1 summarises the associations between p-STAT3 immunoreactivity and the pathological features of the adenocarcinomas. p-STAT3 expression was found in 29 of the 45 well differentiated adenocarcinomas, 34 of the 41 moderately differentiated adenocarcinomas, one of the three poorly differentiated adenocarcinomas, and five of the six

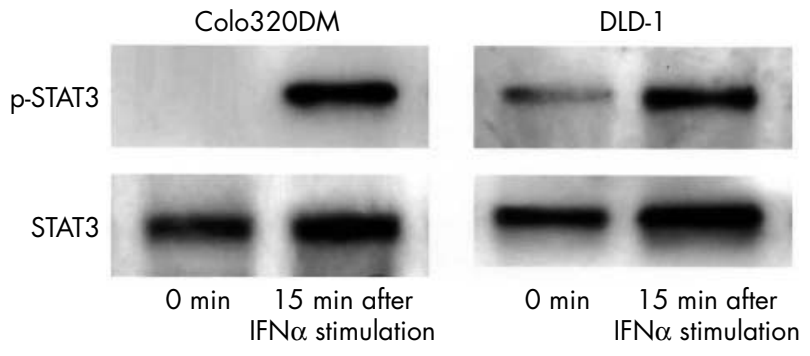

Figure 4 Phosphorylated (activated) signal transducer and activator of transcription (p-STAT3) is constitutively expressed without interferon $\alpha$ (IFN $\alpha$ ) stimulation in the DLD-1 cell line. Colo320DM expressed p-STAT3 only after the stimulation with IFN $\alpha$. mucinous carcinomas. There was no significant correlation between p-STAT3 immunoreactivity and the differentiation of colorectal adenocarcinomas.

p-STAT3 immunoreactivity was compared with the depth of tumour invasion. p-STAT3 expression was found in nine of the 18 Tis tumours, in four of the eight Tl tumours, in two of the five $\mathrm{T} 2$ tumours, in 51 of the $61 \mathrm{~T} 3$ tumours, and in all three T4 tumours. A significant correlation was found between p-STAT3 immunoreactivity and the depth of tumour invasion $(\mathrm{p}<0.01)$.

Lymphatic invasion and venous invasion were found in 30 of 95 and 58 of 95 tumours, respectively. p-STAT3 immunoreactivity was significantly correlated with the presence of venous invasion $(p<0.05)$.

Immunoreactivity at the primary site of colorectal carcinoma significantly correlated with the presence of lymph node metastasis $(p<0.05)$. Immunoreactivity for $p$-STAT3 also correlated with increasing stages of the Dukes' classification $(\mathrm{p}<0.001)$.

Figure 3 shows the results of western blotting for p-STAT3 in surgical specimens of human colorectal cancer. STAT3 expression was detected in all samples. p-STAT3 expression was detected in normal colon mucosa (lanes 1,2), whereas strong expression of p-STAT3 was seen in the colon carcinoma tissues (lanes 3-8).

Figure 4 shows the results of western blotting for p-STAT3 expression in human colorectal carcinoma cell lines. STAT3 expression was detected in both of the colorectal carcinoma cell lines tested. p-STAT3 expression after IFN $\alpha$ stimulation was detected in both colorectal carcinoma cell lines, whereas weak expression of p-STAT3 without IFN $\alpha$ stimulation was seen in one of colorectal carcinoma cell lines. 


\section{DISCUSSION}

In recent years, many reports have suggested a crucial role for the STAT3 signalling pathway in malignant transformation and tumour progression. ${ }^{25}$ In our study, we found a correlation between the expression of p-STAT3 and the depth of tumour invasion in human colorectal adenocarcinomas. The expression of p-STAT3 was found to be more intense in the deeper invasive areas, as shown in fig 2 . Therefore, it is possible that the phosphorylation of STAT3 is upregulated in the advanced stages of invasion. The invasion of tumour cells induces lymph node metastasis and venous invasion. This is consistent with our results, which showed a significant correlation between p-STAT3 immunoreactivity and the presence of lymph node metastasis and venous invasion. Ma et al reported that there was a significant correlation between the expression of p-STAT3 and the presence of lymph node metastasis and invasion in human colorectal carcinoma. ${ }^{26}$ Moreover, Masuda et al also reported that the expression of p-STAT3 significantly correlated with stage in human squamous cell carcinoma of the head and neck. ${ }^{27}$ This suggests that the activation of STAT3 might play an important role in the invasion and metastasis of carcinomas.

STAT3 is activated by phosphorylation at Tyr705, which induces dimerisation, nuclear translocation, and DNA binding. ${ }^{24} 28$ We used an antibody to p-STAT3 (Tyr705), which detects STAT3 only when phosphorylated at Tyr705. Small amounts of p-STAT3 (Tyr705) can be detected in the cytoplasm without stimulation, ${ }^{29}$ although certain cytokines, such as interleukin 6 (IL-6), upregulate the phosphorylation of STAT3, which then moves from the cytoplasm into the nucleus. ${ }^{29}$ In our study, normal mucosa faintly expressed pSTAT3 in the cytoplasm. However, colorectal adenocarcinoma cells expressed p-STAT3 intensely in both the cytoplasm and the nucleus. Although no data are available on the expression of cytokines in colorectal adenocarcinoma, some cytokines may contribute to the activation of STAT3 in colorectal adenocarcinoma.

\section{"Activated STAT3 may regulate tumour growth and metastasis by affecting the expression of genes related to tumour invasion, angiogenesis, the cell cycle, and cell survival"}

The STAT transcription factor family has recently been reported to regulate directly the genes of the Bcl-2 family, which are key regulators of apoptosis in normal mucosa and adenocarcinoma. ${ }^{30}$ Concentrations of the antiapoptotic proteins of this family are increased in response to gpl30 induced activation of STAT3, and some cytokines, such as IL6, may have an effect on the mucosal system by upregulating antiapoptotic proteins. ${ }^{31}$ Members of the Bcl-2 family of proteins are known to be expressed in epithelial cells of the normal colonic crypts. ${ }^{32}$ Treatment with IL-6 induced a dose dependent increase in the concentration of the Bcl-2 protein. ${ }^{31}$ Some reports have shown that IL-6 induces the phosphorylation of STAT3 in normal mucosa. ${ }^{33}$ Therefore, the activation of STAT3 is involved in protecting colonic epithelial cells from cell death.

In our study, we demonstrated constitutive activation of STAT3 in colorectal carcinoma cell lines and colorectal specimens. Xie et al reported that STAT3 upregulated the expression of matrix metalloproteinase 2, and that this correlated with metastasis and invasion in carcinoma. ${ }^{34}{ }^{35}$ In addition, some groups have shown that activated STAT3 directly upregulates the transcription of vascular endothelial growth factor, ${ }^{36}{ }^{37}$ cyclin $\mathrm{Dl},{ }^{38}$ and the c-myc oncogene. ${ }^{39}$ Other groups have reported that p-STAT3 downregulates the expression of antiapoptotic genes Bcl-xL and Mcl- $1 .{ }^{40}{ }^{41}$ Thus,

\section{Take home messages}

- Phosphorylated (activated) signal transducer and activator of transcription ( $p$-STAT3) expression significantly correlated with the depth of tumour invasion, venous invasion, lymph node metastasis, and increasing stages of the Dukes' classification

- To the best of our knowledge, this is the first study to report a significant correlation between p-STAT3 expression and the depth of tumour invasion in colorectal adenocarcinoma

- $\mathrm{p}$-STAT3 expression appears to be an important factor in the carcinogenesis and/or fumour invasion of colorectal adenocarcinoma

activated STAT3 may regulate tumour growth and metastasis by affecting the expression of genes related to tumour invasion, angiogenesis, the cell cycle, and cell survival.

STATs are tyrosine phosphorylated transcription factors activated by JAK family kinases. ${ }^{42}{ }^{43}$ Various ligands, including interferons and growth factors, induce the activation of the JAK kinases, which in turn induce the activation of the STATs. ${ }^{11}{ }^{43}$ STAT3 is activated by IL-6 or IFN $\alpha .{ }^{24}$ IFN $\alpha$ upregulated the expression of p-STAT3 in one of the cell lines used in our study, Colo 320DM cells (fig 4). Some reports have shown that IL-6 expression correlates with carcinogenesis and/or tumour progression. ${ }^{44}{ }^{45}$ Although we did not examine the expression of cytokine receptors, the constitutive activation of STAT3 might be induced by the stimulation of certain cytokines or interferons that activate the JAK kinases, such as IL-6 or IFN $\alpha$. Such a possibility awaits further studies for confirmation.

\section{Authors' affiliations}

T Kusaba, T Nakayama, Y Yakata, A Yoshizaki, I Sekine, Department of Molecular Pathology, Nagasaki University Graduate School of Biomedical Sciences, 1-12-4 Sakamoto, Nagasaki, 852-8523, Japan

T Kusaba, K Yamazumi, T Nagayasu, Department of Translational Medical Sciences, Nagasaki University Graduate School of Biomedical Sciences

\section{REFERENCE}

1 Newland RC, Dent OF, Lyttle MN, et al. Pathologic determinants of survival associated with colorectal cancer with lymph node metastases. A multivariate analysis of 579 patients. Cancer 1994;73:2076-82.

2 Steinberg SM, Barwick KW, Stablein DM. Importance of tumour pathology and morphology in patients with surgically resected colon cancer. Cancer 1986:58:1340-45.

3 Takeda K, Noguchi K, Shi W, et al. Targeted disruption of the mouse Stat3 gene leads to early embryonic lethality. Proc Natl Acad Sci U S A 1997;94:3801-04.

4 Darnell JE Jr. STATs and gene regulation. Science 1997;277:1630-35.

5 Zhong Z, Wen Z, Darnell JE Jr. STAT 3 and STAT 4: members of the family of signal transducers and activators of transcription. Proc Natl Acad Sci U S A 1994;91:4806-10.

6 Chakraborty A, Tweardy D. STAT 3 and G-CSF-induced myeloid differentiation. Leuk Lymphoma 1998;30:433-42.

7 Chakraborty A, Tweardy D. Granulocyte colony-stimulating factor activates a $72-k$ Da isoform of STAT 3 in human neutrophils. J Leukoc Biol 1998;64:675-80.

8 Zhong Z, Wen Z, Darnell JE Jr. STAT 3: a STAT family member activated by tyrosine phosphorylation in response to epidermal growth factor and interleukin-6. Science 1994;267:95-8.

9 Takeda K, Noguchi K, Shi W, et al. Targeted disruption of the mouse Stat3 gene leads to early embryonic lethality. Proc Natl Acad Sci U S A 1997; $94: 3801-4$

10 Scholz A, Heinze S, Detjen KM, et al. Activated signal transducer and activator of transcription 3 (STAT3) supports the malignant phenotype of human pancreatic cancer. Gastroenterology 2003;125:891-905.

11 Bowman T, Garcia R, Turkson J, et al. STATs in oncogenesis. Oncogene 2000;19:2474-88. 
12 Huang M, Page C, Reynolds KR, et al. Constitutive activation Stat3 oncogene product in ovarian carcinoma cells. Gynecol Oncol 2000;79:67-73.

13 Song JI, Grandis JR. STAT signaling in head and neck cancer. Oncogene 2000; 19:2489-95.

14 Jass JR, Sobin LH. Histological typing of intestinal tumours, 2nd ed. Berlin: Springer-Verlag, 1989.

15 Greene FL, Page DL, Fleming ID, et al, eds. AJCC cancer staging manual, 6th ed. New York: Springer Verlag, 2002.

16 Dukes CE. The classification of cancer of the rectum. J Pathol Bacteriol 1932;35:323-32.

17 Dukes CE. The surgical pathology of rectal cancer. J Clin Pathol 1949;2:95-8.

18 Whittaker M, Goligher JC. The prognosis after surgical treatment for carcinoma of the rectum. Br J Surg 1976;63:384-8.

19 Seefeld PH, Bargen JA. The spread of cancer of the rectum: invasion of the lymphatics, veins and nerves. Ann Surg 1943;118:76-89.

20 Talbot IC, Ritchie S, Leighton $M$, et al. Invasion of veins by carcinoma of the rectum: methods of detection, histological features and significance. Histopathology 1981;5:141-63.

21 Campbell CL, Jiang Z, Savarese DM, et al. Increased expression of the interleukin-11 receptor and evidence of STAT3 activation in prostate carcinoma. Am J Pathol 2001;158:25-32.

22 Tsuiji H, Hayashi M, Wynn DM, et al. Expression of mucin-associated sulfoLea carbohydrate epitopes on human colon carcinoma cells. Jpn J Cancer Res 1998:89:1267-75.

23 Hara A, Yoshimi N, Niwa M, et al. Apoptosis induced by NS-398, a selective cyclooxygenase-2 inhibitor, in human colorectal cancer cell lines. Jpn J Cance Res 1997;88:600-4.

24 Darnell JE Jr, Kerr IM, Stark GR. Jak-STAT pathways and transcriptional activation in response to IFNs and other extracellular signaling proteins. Science 1994;264:1415-21.

25 Bromberg J. Stat proteins and oncogenesis. J Clin Invest 2002;109:1139-42.

26 Ma XT, Wang S, Ye YJ, et al. Constitutive activation of Stat3 signaling pathway in human colorectal carcinoma. World J Gastroentero 2004;10:1569-73.

27 Nagpal JK, Mishra R, Das BR. Activation of Stat-3 as one of the early events in tobacco chewing-mediated oral carcinogenesis. Cancer 2002;94:2393-400.

28 Ihle JN. Cytokine receptor signalling. Nature 1995;377:591-4.

29 Pranada AL, Metz S, Herrmann A, et al. Real time analysis of STAT3 nucleocytoplasmic shuttling. J Biol Chem 2004;279:15114-23.

30 Zushi S, Shinomura Y, Kiyohara T, et al. STAT3 mediates the survival signal in oncogenic ras-transfected intestinal epithelial cells. Int J Cancer 1998;78:326-30.

31 Leu CM, Wong FH, Chang C, et al. Interleukin-6 acts as an antiapoptotic factor in human esophageal carcinoma cells through the activation of both
STAT3 and mitogen-activated protein kinase pathways. Oncogene 2003;22:7809-18.

32 Harnois C, Demers MJ, Bouchard V, et al. Human intestinal epithelial crypt cell survival and death: complex modulations of $\mathrm{Bcl}-2$ homologs by Fak, $\mathrm{PI} 3-\mathrm{K} /$ Akt-1, MEK/Erk, and p38 signaling pathways. J Cell Physiol 2004; 19:209-22

33 Hierholzer C, Kalff JC, Chakraborty A, et al. Impaired gut contractility following hemorrhagic shock is accompanied by IL-6 and G-CSF production and neutrophil infiltration. Dig Dis Sci 2001;46:230-41.

34 Xie TX, Wei D, Liu M, et al. Stat3 activation regulates the expression of matrix metalloproteinase- 2 and tumor invasion and metastasis. Oncogene 2004;23:3550-60.

35 Emmert-Buck MR, Roth MJ, Zhuang Z, et al. Increased gelatinase A (MMP-2) and cathepsin $B$ activity in invasive tumor regions of human colon cancer samples. Am J Pathol 1994;145:1285-90.

36 Niu G, Wright KL, Huang $M$, et al. Constitutive Stat3 activity up-regulates VEGF expression and tumor angiogenesis. Oncogene 2002;21:2000-8.

37 Wei LH, Kuo ML, Chen CA, et al. Interleukin-6 promotes cervical tumor growth by VEGF-dependent angiogenesis via a STAT3 pathway. Oncogene 2003;22:1517-27.

38 Bromberg JF, Wrzeszczynska MH, Devgan G, et al. Stat3 as an oncogene. Cell 1999;98:295-303.

39 Nakajima K, Yamanaka Y, Nakae K, et al. A central role for Stat3 in IL-6induced regulation of growth and differentiation in $\mathrm{Ml}$ leukemia cells. EMBO J $1996 ; 15: 3651-58$

40 Catlett-Falcone $\mathbf{R}$, Landowski TH, Oshiro MM, et al. Constitutive activation of Stat3 signaling confers resistance to apoptosis in human U266 myeloma cells. Immunity 1999;10:105-15.

41 Niu G, Bowman T, Huang M, et al. Roles of activated Src and Stat3 signaling in melanoma tumor cell growth. Oncogene 2002;21:7001-10.

42 Huang M, Page C, Reynolds RK, et al. Constitutive activation of stat 3 oncogene product in human ovarian carcinoma cells. Gynecol Oncol 2000;79:67-73.

43 Shizuo Akira. Roles of STAT3 defined by tissue-specific gene targeting Oncogene 2000; 19:2607-11.

44 Schneider MR, Hoeflich A, Fischer JR, et al. Interleukin-6 stimulates clonogenic growth of primary and growth of primary and metastatic human colon carcinoma cells. Cancer Lett 2000;151:31-8.

45 Dansky-Ullmann C, Salgaller M, Adams S, et al. Synergistic effects of IL-6 and IFN-gamma on carcinoembryonic antigen (CEA) and HLA expression by human colorectal carcinoma cells: role for endogenous IFN-beta. Cytokine 1995:7:118-29. 